\title{
Fructose-enhanced reduction of bacterial growth on nanorough surfaces
}

This article was published in the following Dove Press journal:

International Journal of Nanomedicine

31 January 2012

Number of times this article has been viewed

\section{Naside Gozde Durmus' \\ Erik N Taylor' \\ Fatih Inci ${ }^{3,4}$ \\ Kim M Kummer' \\ Keiko M Tarquinio ${ }^{5}$ \\ Thomas J Webster ${ }^{1,2}$}

'School of Engineering, Brown University, Providence, RI, USA; ${ }^{2}$ Department of Orthopedics, Brown University, Providence, RI, USA; ${ }^{3}$ Bio-Acoustic-MEMS in Medicine (BAMM) Laboratory, Center for Biomedical Engineering, Department of Medicine, Brigham and Women's Hospital, Harvard-MIT Health Sciences and Technology, Harvard Medical School, MA, USA; ${ }^{4}$ Istanbul Technical University, Molecular Biology-Genetics and Biotechnology Program, Mobgam, Maslak, Istanbul, Turkey; ${ }^{5}$ Division of Pediatric Critical Care Medicine, Rhode Island Hospital, Providence, RI, USA
Correspondence: Thomas J Webster School of Engineering and Department of Orthopedics, Brown University, Providence, RI 02912 USA

$\mathrm{Tel}+\mathrm{I} 40 \mid 8632318$

Fax $+\mid$ 40I 8631309

Email thomas_webster@brown.edu
Abstract: Patients on mechanical ventilators for extended periods of time often face the risk of developing ventilator-associated pneumonia. During the ventilation process, patients incapable of breathing are intubated with polyvinyl chloride (PVC) endotracheal tubes (ETTs). PVC ETTs provide surfaces where bacteria can attach and proliferate from the contaminated oropharyngeal space to the sterile bronchoalveolar area. To overcome this problem, ETTs can be coated with antimicrobial agents. However, such coatings may easily delaminate during use. Recently, it has been shown that changes in material topography at the nanometer level can provide antibacterial properties. In addition, some metabolites, such as fructose, have been found to increase the efficiency of antibiotics used to treat Staphylococcus aureus (S. aureus) infections. In this study, we combined the antibacterial effect of nanorough ETT topographies with sugar metabolites to decrease bacterial growth and biofilm formation on ETTs. We present for the first time that the presence of fructose on the nanorough surfaces decreases the number of planktonic $S$. aureus bacteria in the solution and biofilm formation on the surface after 24 hours. We thus envision that this method has the potential to impact the future of surface engineering of biomaterials leading to more successful clinical outcomes in terms of longer ETT lifetimes, minimized infections, and decreased antibiotic usage; all of which can decrease the presence of antibiotic resistant bacteria in the clinical setting.

Keywords: antibacterial, medical device infection, ventilator-associated pneumonia, endotracheal tubes, nanoroughness, fructose, Staphylococcus aureus

\section{Introduction}

Ventilator-associated pneumonia (VAP) is the most common hospital-acquired infection among patients requiring mechanical ventilation. ${ }^{1-3}$ Patients are intubated with endotracheal tubes (ETTs) which interact with the surrounding airway epithelium during the ventilation process. On the other hand, ETTs provide surfaces where bacteria can attach, colonize and proliferate from the contaminated oropharyngeal space to the sterile bronchoalveolar area. ${ }^{4,5}$ Prolonged intubation leads to the colonization of the upper respiratory tract by pathogens such as Pseudomonas aeruginosa ( . aeruginosa) and Staphylococcus aureus (S. aureus) and increases the risk of lung infection by sixfold to twenty-fold..$^{2,3,6-8}$ In addition, the risk of VAP increases by $3 \%$ per day during the first 5 days of mechanical ventilation and by $2 \%$ between days 5 and $10 .^{5-9}$ Therefore, there exists an unmet clinical need to create surfaces that resist bacterial attachment and growth to reduce the risk of infection.

Surfaces of invasive medical devices serve as substrates for bacterial attachment, growth, colonization, and biofilm formation. ${ }^{10,11}$ Bacterial biofilms are complex 
heterogeneous communities embedded in an extracellular polymeric substance (EPS) matrix which is composed of polysaccharides, nucleic acids, proteins, and lipids. ${ }^{12,13}$ The formation of these sessile (adherent, immobile bacteria) communities provides a resistance mechanism against host immune responses and antibacterial agents. ${ }^{14}$ Inherent resistance of biofilms on material surfaces causes a real-world problem as many persistent and chronic bacterial infections occur in medical and industrial settings.

There is a growing interest in using nanotechnology (or the use of novel materials with at least one constituent dimension $<100 \mathrm{~nm}$ ) approaches for the treatment of bacterial infections. ${ }^{11,15-17}$ Recently, many studies have shown that changes in the surface topography at the nanometer level can interfere with mammalian cell as well as bacterial cell functions..$^{4,18-33}$ Conventional biomaterials do not have nanoscale roughness. Nanoscale materials provide roughness and dimensions at the nano level which might influence bacteria behavior. ${ }^{4,25}$ An in vitro study recently reported decreased Staphylococcus epidermidis (S. epidermidis) attachment on nanostructured $\mathrm{ZnO}$ and titania $\left(\mathrm{TiO}_{2}\right)$ compared to microstructured surface features. ${ }^{23}$ It was also demonstrated that the attachment of different pathogenic strains ( $S$. aureus, $S$. epidermidis, and $P$. aeruginosa) could be controlled by changing titanium surface roughness and ultrafine crystallinity at the nano level. ${ }^{22}$ Medical device surfaces can be modified with silver nanoparticles to improve their antibacterial effects. ${ }^{34,35}$ Silver nanoparticles also influenced the antibacterial properties of montmorillonite/chitosan bionanocomposites. ${ }^{36}$ These nanotopographical effects on bacteria might be due to changes in surface energy leading to changes in the adsorbed protein layer which modulates intercellular interactions. ${ }^{37,38}$ For example, increased protein adsorption and bioactivity on nanostructured titanium surfaces resulted in improved functions of osteoblasts (bone-forming cells). 22,27,39-42 Nanostructured hydroxyapatite-poly-lactideco-glycolide (PLGA) composites also promoted adhesioninduced osteogenic differentiation of human mesenchymal stem cells. ${ }^{43}$ Moreover, an approximate $40 \%$ reduction in colony forming units was observed on nanorough polyvinyl chloride (PVC) ETT surfaces compared to conventional ETTs. ${ }^{4,24}$ These studies indicated that there is a great potential to create antibacterial surfaces via engineering surface roughness at the nanoscale.

In addition to the antibacterial effects of surface nanoroughness, eradication of biofilms can be controlled by changing the surrounding microenvironment and biological conditions. Persister bacteria represent a population of dormant cells which can form biofilms in chronic infections. ${ }^{13,44}$ Persisters enter a metabolic hibernation state and shut down their metabolism. This enables them to survive during the antibiotic treatment and become resistant. A recent study provided evidence that the addition of certain metabolites, such as fructose, could increase the efficiency of antibiotics which are used to treat both Gram-negative and Grampositive persisters. ${ }^{44}$ In this approach, persister bacteria are stimulated into an active state using fructose metabolites. Fructose molecules enter the bacterial metabolism through glycolysis and stimulate the shutdown metabolism of persister cells. As a result, changes in the bacterial metabolism stimulate the uptake of antibiotics. Therefore, fructose metabolites combined with an aminoglycoside antibiotic (ie, gentamicin) render biofilm forming bacteria vulnerable to antibiotic treatment and eradicate them from the medical device surfaces. ${ }^{44}$ Metabolites which can trigger and enable the dispersal of biofilms have a great potential to treat infections in the clinical settings.

In this study, we combined the antibacterial effect of nanorough topographies with specific sugar metabolites to further decrease bacterial growth and biofilm formation on ETTs without using antibiotics. S. aureus was chosen as the target bacteria as it is one of the major causes of fatal nosocomial infections as well as community-associated infections. In addition, it is the most frequently isolated bacteria in patients whose episode of VAP was diagnosed during the first days of mechanical ventilation. ${ }^{1,45}$ The experimental strategy employed in our work is shown in Figure 1. First, commercially available PVC ETTs were enzymatically

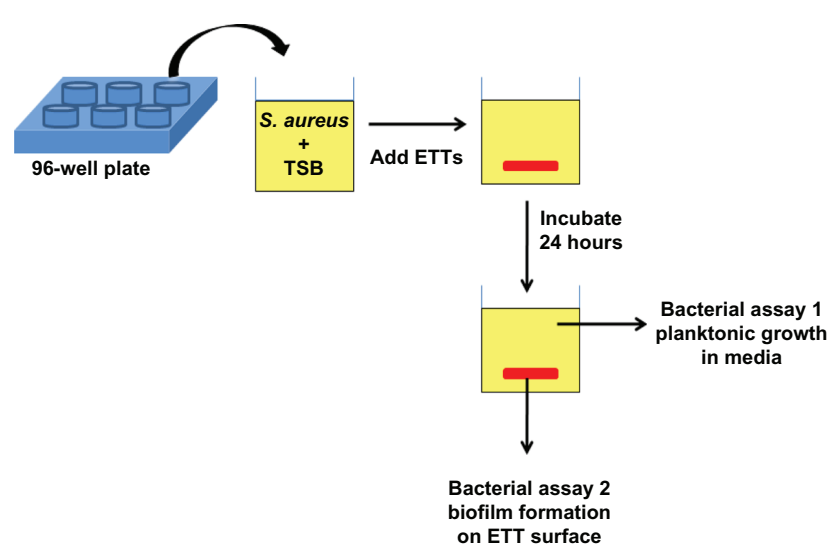

Figure I Schematic of bacteria assays. Commercially available PVC ETTs were enzymatically degraded to create nanoscale surface roughness. Then, control PVC and NanoR ETTs were soaked into different concentrations of a fructose solution. Bacterial survival in the medium (assay I) and biofilm formation on the ETT surfaces (assay 2) were quantified.

Abbreviations: ETT, endotracheal tube; NanoR, nanorough; PVC, polyvinyl chloride; TBS, tryptic soy broth. 
degraded to create nanoscale surface roughness. Then, the nanorough (NanoR) ETTs were soaked in different concentrations of a fructose solution. Planktonic bacterial growth in the surrounding culture medium and biofilm formation of S. aureus on ETT surfaces were observed and quantified after 24 hours. We present for the first time that the presence of a specific metabolite, ie, fructose, on the nanorough PVC ETT surfaces decreases the number of planktonic bacteria in the solution and biofilm formation after 24 hours.

\section{Materials and methods PVC ETT material preparation and nanoroughening}

Commercially available Sheridan ${ }^{\circledR} 6.0 \mathrm{~mm}$ ID, uncuffed ETTs (Hudson RIC, Temecula, CA) were cut vertically into $0.6 \mathrm{~cm} \times 0.3 \mathrm{~cm}$ segments using a rectangular hole punch. Nanorough (NanoR) topographies on the PVC ETT surface were created using a lipase from Rhizopus arrhizus (Sigma-Aldrich, St Louis, MO) at a $0.1 \%$ concentration in $1 \mathrm{M}$ potassium phosphate buffer (PBS) at a $\mathrm{pH}$ of 7.2 (Fisher Scientific, Waltham, MA). PVC samples were soaked in the lipase solution at $37^{\circ} \mathrm{C}, 200 \mathrm{rpm}$ for 24 hours. After 24 hours, the lipase solution was replaced with a fresh solution and the samples were soaked for an additional 24 hours. Then, the NanoR samples were removed and rinsed three times with double distilled water. The NanoR and untreated PVC samples were air dried overnight (approximately 12 hours) at room temperature, and then they were sterilized using ethylene oxide gas.

\section{PVC surface modification with metabolites}

D-Fructose (Fisher Scientific, Pittsburgh, PA) was dissolved in double distilled water. The fructose solution was sterilized via a polytetrafluoroethylene (PTFE) syringe filter with a $0.2 \mu \mathrm{m}$ pore size (Fisher Scientific, Pittsburgh, PA). To coat surfaces with the fructose, sterilized PVC samples prepared above were soaked in $10 \mathrm{mM}$ and $100 \mathrm{mM}$ fructose solutions and incubated overnight (approximately 12 hours) in a sterile hood. Then, the samples were air dried in the sterile hood.

\section{Surface characterization}

\section{Scanning electron microscopy (SEM)}

Surface topography of the materials was visualized using an SEM (LEO 1530VP FE-4800 Field-Emission SEM, Carl Zeiss SMT, Peabody, MA) according to standard operating procedures. Samples were imaged with an accelerating voltage of $20 \mathrm{kV}$ using variable pressure.

\section{Atomic force microscopy (AFM)}

Samples were further characterized using atomic force microscopy (AFM) with scan areas of $5 \mu \mathrm{m} \times 5 \mu \mathrm{m}$. The topography of the PVC substrates were evaluated with AFM (Asylum-1 MFP-3D AFM System, Santa Barbara, CA) under tapping mode using a $9 \mathrm{~nm} \pm 2 \mathrm{~nm}$ AFM tip with a scan rate of $0.5 \mathrm{~Hz}$. The root-mean-squared (RMS) roughness, which is the standard deviation of the height value in the selected line, was determined in five random fields per sample.

\section{Contact angle measurements}

Water contact angles were investigated using a drop shape analysis system (EasyDrop, Kruss, Hamburg, Germany). The contact angle from $1 \mu \mathrm{L}$ of double distilled water sessile droplets ( 60 seconds after being dropped on the surface) was measured for each sample.

\section{Bacteria assays}

\section{Bacteria culture}

S. aureus (ATCC number 25923, American Type Culture Collection, Mannassas, VA) was hydrated and streaked for isolation on a tryptic soy agar plate. Following growth, a single isolated colony was selected and inoculated in $3 \mathrm{~mL}$ of tryptic soy broth (TSB) media (MP Biomedicals, Solon, $\mathrm{OH})$. The bacteria culture was grown on an incubator shaker for 18 hours at $37^{\circ} \mathrm{C}, 200 \mathrm{rpm}$ until it reached the stationary phase.

\section{Bacterial growth and biofilm formation analyses}

First, the optical density of the overnight culture at $562 \mathrm{~nm}$ $\left(\mathrm{OD}_{562}\right)$ was adjusted to 0.52 , which corresponds to a cell number of $10^{9}$. Then, the cultures were serially diluted to obtain a $10^{3}$ bacteria solution. One hundred microliters of a $10^{3}$ bacteria solution was seeded onto a single well of a flat bottom 96-well plate (BD Biosciences, Franklin Janes, NJ) containing either NanoR or an untreated PVC sample soaked in a $10 \mathrm{mM}$ and $100 \mathrm{mM}$ fructose solution. Unsoaked NanoR and PVC samples were used as controls. The plate was then placed in a stationary incubator at $37^{\circ} \mathrm{C}$ with $5 \% \mathrm{CO}_{2}$. After 24 hours, samples were removed with a pair of sterile forceps. Optical density of the plate was then measured at $562 \mathrm{~nm}$ using a SpectraMax M5 plate reader (Molecular Devices, Sunnyvale, CA) to analyze the planktonic bacteria growth. To remove sessile bacteria from the PVC surface, a vortexing method was used and a cell viability assay was performed to measure colony forming units $/ \mathrm{mL}(\mathrm{CFU} / \mathrm{mL})$. Specifically, each PVC sample was placed in $1 \mathrm{~mL}$ of PBS (Fisher Scientific) and vortexed at $3000 \mathrm{rpm}$ for 10 minutes. The cells 
were then serially diluted in PBS (Fisher Scientific) over a 3-log range. Ten microliters of each dilution were plated on tryptic soy agar plates and incubated at $37^{\circ} \mathrm{C}$ overnight. After overnight incubation, colony forming units were counted for each sample to quantify biofilm formation on the ETT surfaces. CFU/mL values were calculated using the following formula:

$$
\begin{aligned}
\mathrm{CFU} / \mathrm{mL}= & ([\text { (Number of colonies }) \\
& \times(\text { Dilution factor })] / 0.01 \mathrm{~mL})
\end{aligned}
$$

\section{Statistical analysis}

All experiments were performed in triplicate and repeated at least three times to validate repeatability and reproducibility.
Data were represented as the mean \pm standard error of the mean (SEM). Results were analyzed for statistical significance using a Student's $t$-test (unpaired) and Microsoft Excel software (Redmond, WA). Three different significance levels $(P<0.01, P<0.05$, and $P<0.1)$ were noted.

\section{Results and discussion Material characterization}

SEM analysis indicated that the lipase treatment degraded conventional PVC surfaces and created nanoscale features (Figure 2). In addition, AFM micrographs revealed distinct topographies in control surfaces compared to NanoR PVC surfaces (Figure 3A and B). As expected, control PVC surfaces were smooth compared to NanoR PVC. Roughness of
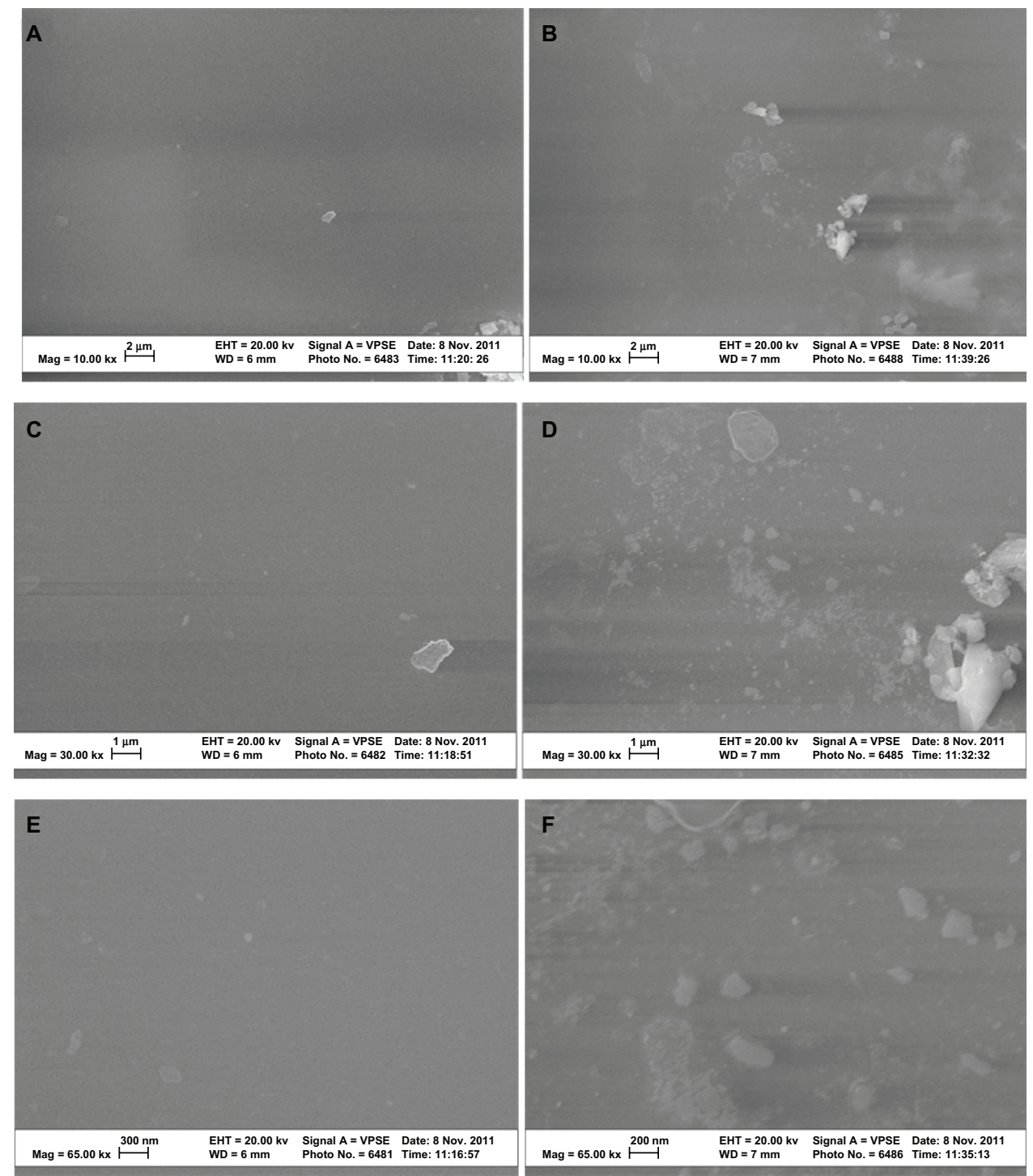

Figure 2 SEM images of untreated PVC and NanoR PVC. Untreated PVC samples revealed a smooth surface (A, 10 KX; C, 30 KX; and E, 65 KX). On the other hand, NanoR PVC samples revealed a rough surface (B, $10 \mathrm{KX}$; D, $30 \mathrm{KX}$; and $\mathbf{F}, 65 \mathrm{KX}$ ).

Abbreviations: NanoR, nanorough; PVC, polyvinyl chloride; SEM, scanning electron microscope. 
A

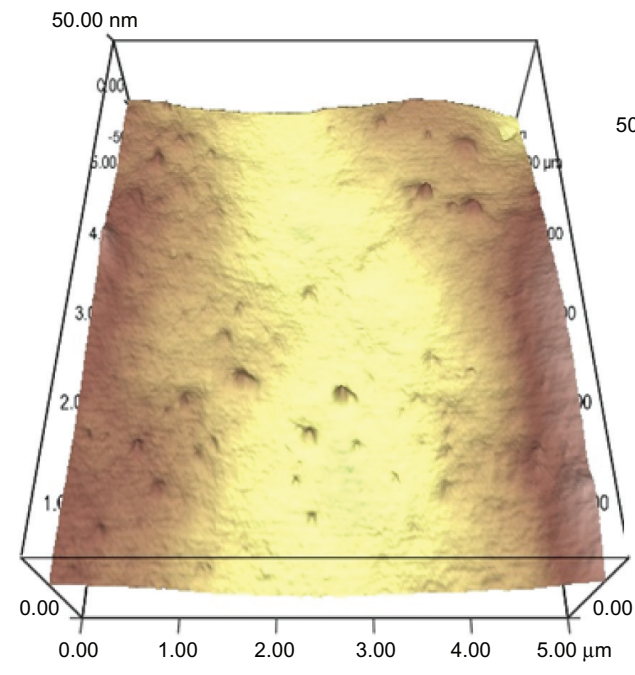

C

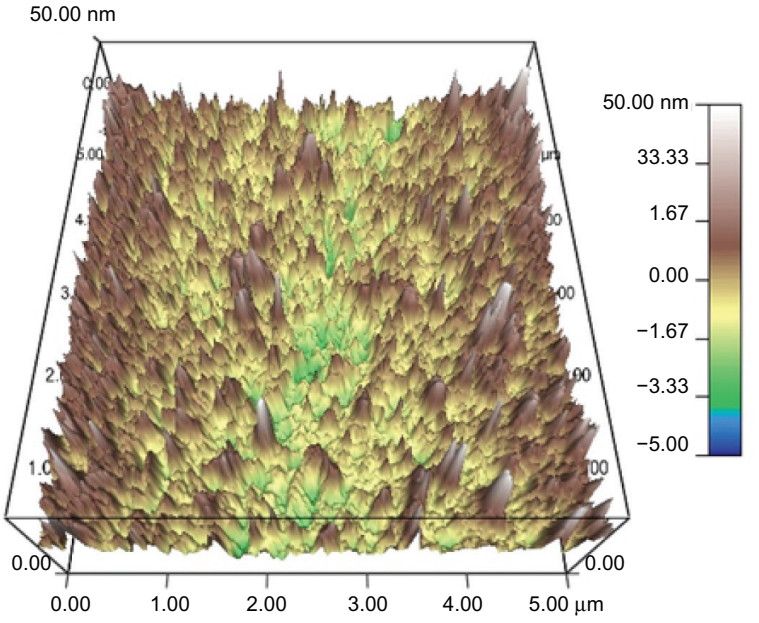

E

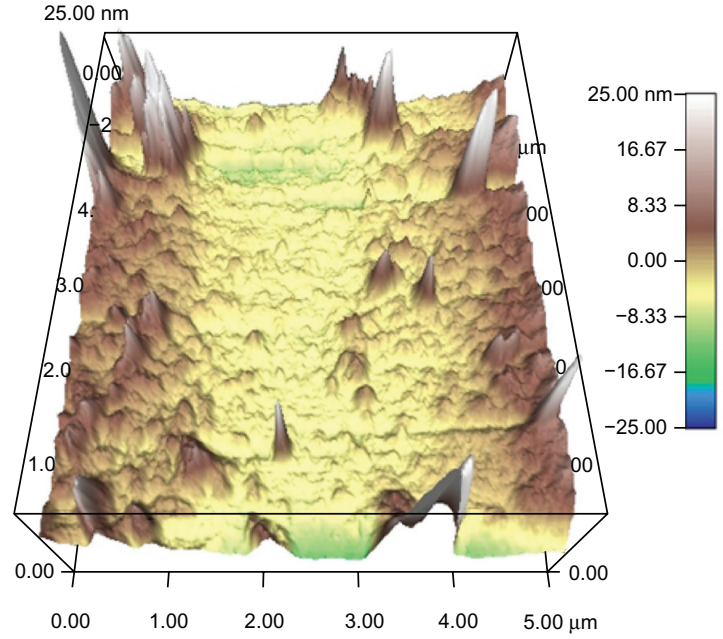

B

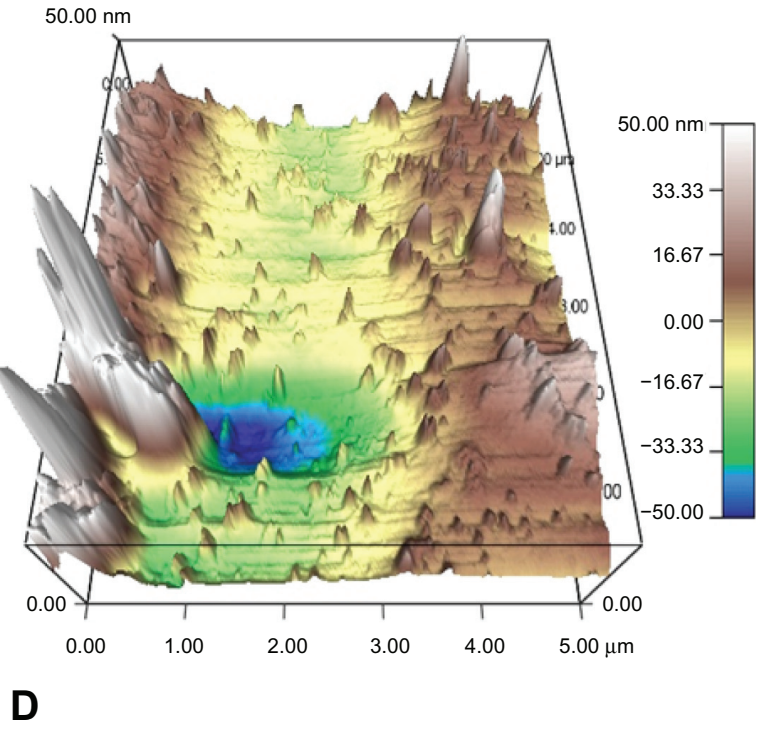

$\mathbf{F}$

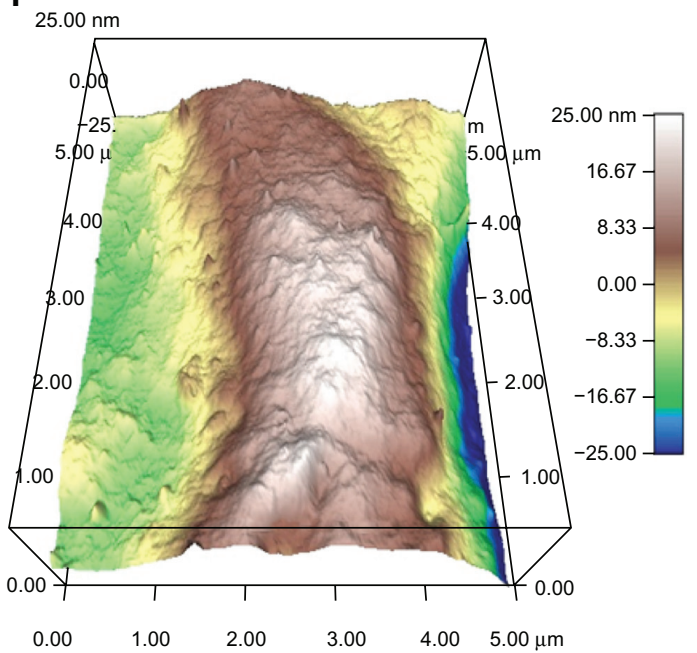

Figure 3 AFM micrographs showing the topography of (A and B) control PVC and NanoR PVC; (C and E) control PVC soaked in 10 mM and I00 mM fructose; and (D and F) NanoR PVC soaked in $10 \mathrm{mM}$ and $100 \mathrm{mM}$ fructose, respectively. Micrographs revealed distinct differences in nanotopographies between the control PVC and NanoR PVC surface soaked in different metabolite concentrations.

Abbreviations: AFM, atomic force microscopy; NanoR, nanorough; PVC, polyvinyl chloride. 
Table 2 Water contact angles on PVC and NanoR PVC surfaces before and after soaking into two different concentrations ( $10 \mathrm{mM}$ and $100 \mathrm{mM}$ ) of a fructose solution

\begin{tabular}{ll}
\hline & Contact angle with $\mathrm{H}_{2} \mathrm{O}$ \\
\hline PVC & $88.62^{\circ} \pm 1.12$ \\
PVC soaked in $10 \mathrm{mM}$ fructose & $72.98^{\circ} \pm 0.45^{*}$ \\
PVC soaked in $100 \mathrm{mM}$ fructose & $69.02^{\circ} \pm 1.43^{*}$ \\
NanoR & $70.36^{\circ} \pm 1.18^{*}$ \\
NanoR soaked in $10 \mathrm{mM}$ fructose & $68.10^{\circ} \pm 3.19^{*}$ \\
NanoR soaked in $100 \mathrm{mM}$ fructose & $64.18^{\circ} \pm 3.46^{*}$ \\
\hline
\end{tabular}

Notes: Values are mean \pm SEM, $n=5 . * P<0.01$ compared to the control PVC ETT surface.

Abbreviations: ETT, endotracheal tube; NanoR, nanorough; PVC, polyvinyl chloride; SEM, standard error of the mean.

$(P<0.05)$. More importantly, all these results were accomplished without using any antibiotics.

Biofilms develop a protected growth situation which allows survival in a hostile environment. As a result, bacterial persisters are a dormant population and they are tolerant to antibiotic treatment. ${ }^{13,14,44}$ These persister structures within biofilms form channels in which nutrient circulation occurs. However, the uptake of some antibiotics, such as aminoglysocides, requires a promotion motive force (PMF). As the biofilm forming bacteria are in a dormant state, they do not uptake or metabolize antibiotics. Thus, bacterial resistance to antibiotics develops. If the metabolites which enter the upper glycolysis metabolism (ie, glucose, fructose, and mannitol) are added into the microenvironment as carbon sources, the efficiency of gentamicin increases. As the metabolism and PMF of the persisters are induced, metabolite stimulation increases the uptake of antibiotics and their killing efficiency. ${ }^{44}$ In addition,

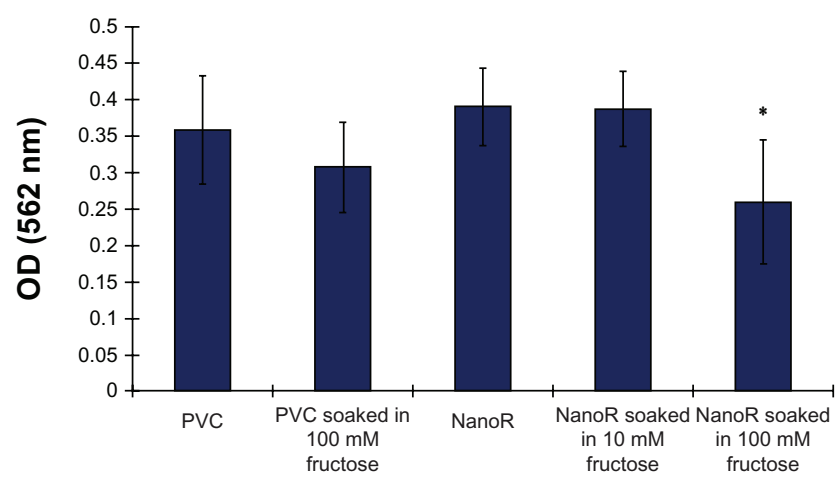

Figure 4 Staphylococcus aureus optical density measurements after 24 hours. Planktonic bacteria growth decreased on NanoR surfaces soaked in a fructose (10 mM and $100 \mathrm{mM})$ solution.

Notes: Data represent mean $\pm \mathrm{SEM}, \mathrm{n}=3$. $* \mathrm{P}<0.05$ NanoR compared to NanoR soaked in $100 \mathrm{mM}$ fructose, NanoR soaked in $10 \mathrm{mM}$ fructose compared to NanoR soaked in $100 \mathrm{mM}$ fructose.

Abbreviations: NanoR, nanorough; OD, optical density; SEM, standard error of the mean.

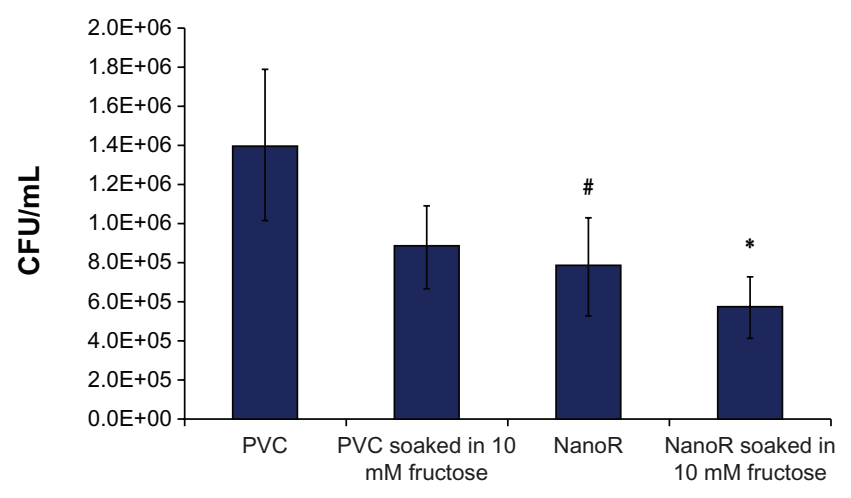

Figure 5 Staphylococcus aureus colony counts on PVC and NanoR surfaces soaked in a $10 \mathrm{mM}$ fructose solution. Biofilm formation decreased on NanoR and PVC surfaces soaked in a $10 \mathrm{mM}$ fructose solution after 24 hours.

Notes: Data represent mean $\pm S E M, n=4 . * P<0.05$ NanoR soaked in a $10 \mathrm{mM}$ fructose solution compared to the PVC control, $\# P<0$.I NanoR compared to the PVC control.

Abbreviations: CFU, colony forming units; NanoR, nanorough; PVC, polyvinyl chloride; SEM, standard error of the mean.

these sessile biofilm communities can give rise to non-sessile bacterium and these planktonic bacteria can rapidly multiply and disperse within the solution. Planktonic bacteria must expose themselves to deleterious agents in their environment while the biofilm forming persisters protect themselves from harsh environmental conditions, such as antibiotics. ${ }^{14}$ As the planktonic bacteria are dispersed within the surrounding medium due to the presence of fructose on the ETT surface, surface roughness at the nanoscale could minimize the contact between the bacteria cell wall and the NanoR ETT surface. This might inhibit the electrostatic interactions responsible for initial bacterial attachment on the surface. ${ }^{4}$ Accumulation of proteins on nanorough surfaces might also affect initial bacterial adhesion though a thick protein layer. ${ }^{51}$ This layer could decrease interactions at the bacteria-nanorough surface interface. Thus, this passivation effect could reduce bacterial attachment and biofilm formation. ${ }^{51}$ Moreover, metabolites on both PVC and NanoR ETT surfaces might induce metabolism of biofilm forming $S$. aureus. All of these events might lead to the reduction of both planktonic bacteria growth and biofilm formation on NanoR surfaces that are soaked in fructose solutions, without the use of any antibiotics. Given the results of this study, the effect of combining nanostructured surfaces with other metabolites which enter bacterial metabolism through glycolysis (such as glucose, mannitol, and pyruvate) could be studied in future studies.

\section{Conclusions}

In summary, we present for the first time that the presence of fructose on nanorough PVC ETT surfaces decreases the number of planktonic $S$. aureus in the solution and biofilm 
formation on the surface, without using any antibiotics. In addition, we showed that engineered nanoscale topographies provide surfaces that are more resistant to bacterial growth than conventional PVC without using any antibiotics. Our results have important implications. First, the design of nanorough engineered surfaces decreases bacterial adhesion on surfaces. In addition, the reduction of biofilm forming bacteria can be improved through the use of specific metabolites on nanorough surfaces. We envision that this method has the potential to impact the future of surface engineering of ETTs as well as catheters and other invasive biomaterials leading to more successful clinical outcomes in terms of longer device lifetimes, minimized infections, and decreased antibiotic usage; all of these events will support the decreased presence of antibiotic resistant bacteria.

\section{Acknowledgments}

The authors thank the Hermann Foundation for funding.

\section{Disclosure}

The authors report no conflict of interest in this work.

\section{References}

1. Rello J, Ollendorf DA, Oster G, et al. Epidemiology and outcomes of ventilator-associated pneumonia in a large US database. Chest. 2002;122(6):2155-2121.

2. Richards MJ, Edwards JR, Culver DH, Gaynes RP. Nosocomial infections in medical intensive care units in the United States. National Nosocomial Infections Surveillance System. Crit Care Med. 1999; 27(5):887-892.

3. Vincent JL, Bihari DJ, Suter PM, et al. The prevalence of nosocomial infection in intensive care units in Europe. Results of the European Prevalence of Infection in Intensive Care (EPIC) Study. EPIC International Advisory Committee. JAMA. 1995;274(8):639-644.

4. Seil JT, Rubien NM, Webster TJ, Tarquinio KM. Comparison of quantification methods illustrates reduced Pseudomonas aeruginosa activity on nanorough polyvinyl chloride. J Biomed Mater Res B Appl Biomater. 2011;98(1):1-7.

5. Raad II, Mohamed JA, Reitzel RA, et al. The prevention of biofilm colonization by multidrug-resistant pathogens that cause ventilator-associated pneumonia with antimicrobial-coated endotracheal tubes. Biomaterials. 2011;32(11):2689-2694.

6. Fagon JY, Chastre J, Domart Y, Trouillet JL, Gibert C. Mortality due to ventilator-associated pneumonia or colonization with Pseudomonas or Acinetobacter species: assessment by quantitative culture of samples obtained by a protected specimen brush. Clin Infect Dis. 1996;23(3): 538-542.

7. Adair CG, Gorman SP, Feron BM, et al. Implications of endotracheal tube biofilm for ventilator-associated pneumonia. Intensive Care Med. 1999;25(10):1072-1076.

8. Sottile FD, Marrie TJ, Prough DS, et al. Nosocomial pulmonary infection: possible etiologic significance of bacterial adhesion to endotracheal tubes. Crit Care Med. 1986;14(4):265-270.

9. Rello J, Torres A, Ricart M, et al. Ventilator-associated pneumonia by Staphylococcus aureus. Comparison of methicillin-resistant and methicillin-sensitive episodes. Am J Respir Crit Care Med. 1994;150(6): $1545-1549$.
10. Antoci V Jr, Adams CS, Parvizi J, et al. The inhibition of Staphylococcus epidermidis biofilm formation by vancomycin-modified titanium alloy and implications for the treatment of periprosthetic infection. Biomaterials. 2008;35:4684-4690.

11. Taylor E, Webster TJ. Reducing infections through nanotechnology and nanoparticles. Int J Nanomedicine. 2011;6:1463-1473.

12. Xavier JB, Picioreanu C, Rani SA, van Loosdrecht MC, Stewart PS. Biofilm-control strategies based on enzymic disruption of the extracellular polymeric substance matrix - a modelling study. Microbiology. 2005;151(Pt 12):3817-3832.

13. Davey ME, O'toole GA. Microbial biofilms: from ecology to molecular genetics. Microbiol Mol Biol Rev. 2000;64(4):847-867.

14. Costerton JW, Stewart PS, Greenberg EP. Bacterial biofilms: a common cause of persistent infections. Science. 1999;284(5418):1318-1322.

15. Tripp RA, Alvarez R, Anderson B, Jones L, Weeks C, Chen W. Bioconjugated nanoparticle detection of respiratory syncytial virus infection. Int J Nanomedicine. 2007;2(1):117-124.

16. Chen M, Yang Z, Wu H, Pan X, Xie X, Wu C. Antimicrobial activity and the mechanism of silver nanoparticle thermosensitive gel. Int $J$ Nanomedicine. 2011;6:2873-2877.

17. Tran PA, Webster TJ. Selenium nanoparticles inhibit Staphylococcus aureus growth. Int J Nanomedicine. 2011;6:1553-1558.

18. Mitik-Dineva N, Wang J, Mocanasu RC, Stoddart PR, Crawford RJ, Ivanova EP. Impact of nano-topography on bacterial attachment. Biotechnol J. 2008;3(4):536-544.

19. Mitik-Dineva N, Wang J, Truong VK, et al. Escherichia coli, Pseudomonas aeruginosa, and Staphylococcus aureus attachment patterns on glass surfaces with nanoscale roughness. Curr Microbiol. 2009;58(3): 268-273.

20. Truong VK, Rundell S, Lapovok R, et al. Effect of ultrafine-grained titanium surfaces on adhesion of bacteria. Appl Microbiol Biotechnol. 2009;83(5):925-937.

21. Ivanova EP, Truong VK, Wang JY, et al. Impact of nanoscale roughness of titanium thin film surfaces on bacterial retention. Langmuir. 2010;26(3):1973-1982.

22. Puckett SD, Taylor E, Raimondo T, Webster TJ. The relationship between the nanostructure of titanium surfaces and bacterial attachment. Biomaterials. 2010;31(4):706-713.

23. Colon G, Ward BC, Webster TJ. Increased osteoblast and decreased Staphylococcus epidermidis functions on nanophase $\mathrm{ZnO}$ and $\mathrm{TiO}_{2}$. J Biomed Mater Res A. 2006;78(3):595-604.

24. Machado MC, Cheng D, Tarquinio KM, Webster TJ. Nanotechnology: pediatric applications. Pediatr Res. 2010;67(5):500-504.

25. Scardino AJ, Zhang H, Cookson DJ, Lamb RN, de Nys R. The role of nano-roughness in antifouling. Biofouling. 2009;25(8):757-767.

26. Samaroo HD, Lu J, Webster TJ. Enhanced endothelial cell density on NiTi surfaces with sub-micron to nanometer roughness. Int $J$ Nanomedicine. 2008;3(1):75-82.

27. Puckett S, Pareta R, Webster TJ. Nano rough micron patterned titanium for directing osteoblast morphology and adhesion. Int J Nanomedicine. 2008;3(2):229-241.

28. Tran P, Webster TJ. Enhanced osteoblast adhesion on nanostructured selenium compacts for anti-cancer orthopedic applications. Int J Nanomedicine. 2008;3(3):391-396.

29. Keshel SH, Azhdadi SN, Asefnejad A, Sadraeian M, Montazeri M, Biazar E. The relationship between cellular adhesion and surface roughness for polyurethane modified by microwave plasma radiation. Int $J$ Nanomedicine. 2011;6:641-647.

30. Park MR, Banks MK, Applegate B, Webster TJ. Influence of nanophase titania topography on bacterial attachment and metabolism. Int J Nanomedicine. 2008;3(4):497-504.

31. Rajyalakshmi A, Ercan B, Balasubramanian K, Webster TJ. Reduced adhesion of macrophages on anodized titanium with select nanotube surface features. Int J Nanomedicine. 2011;6:1765-1771.

32. Zhang L, Chun YW, Webster TJ. Decreased lung carcinoma cell density on select polymer nanometer surface features for lung replacement therapies. Int J Nanomedicine. 2010;13(5):269-275. 
33. Karagkiozaki VC, Logothetidis SD, Kassavetis SN, Giannoglou GD. Nanomedicine for the reduction of the thrombogenicity of stent coatings. Int J Nanomedicine. 2010;7(5):239-248.

34. Juan L, Zhimin Z, Anchun M, Lei L, Jingchao Z. Deposition of silver nanoparticles on titanium surface for antibacterial effect. Int $J$ Nanomedicine. 2010;5:261-267.

35. Liao J, Anchun M, Zhu Z, Quan Y. Antibacterial titanium plate deposited by silver nanoparticles exhibits cell compatibility. Int J Nanomedicine. 2010;13(5):337-342.

36. Shameli K, Ahmad MB, Yunus WM, et al. Green synthesis of silver/ montmorillonite/chitosan bionanocomposites using the UV irradiation method and evaluation of antibacterial activity. Int $J$ Nanomedicine. 2010;5:875-887.

37. Lord MS, Foss M, Besenbacher F. Influence of nanoscale surface topography on protein adsorption and cellular response. Nanotoday. 2010;5(1):66-78.

38. Tuttle PV, Rundell AE, Webster TJ. Influence of biologically inspired nanometer surface roughness on antigen-antibody interactions for immunoassay-biosensor applications. Int J Nanomedicine. 2006;1(4): 497-505.

39. Webster TJ, Ergun C, Doremus RH, Siegel RW, Bizios R. Specific proteins mediate enhanced osteoblast adhesion on nanophase ceramics. J Biomed Mater Res. 2000;51(3):475-483.

40. Woo KM, Chen VJ, Ma PX. Nano-fibrous scaffolding architecture selectively enhances protein adsorption contributing to cell attachment. J Biomed Mater Res A. 2003;67(2):531-537.

41. Ercan B, Webster TJ. Greater osteoblast proliferation on anodized nanotubular titanium upon electrical stimulation. Int J Nanomedicine. 2008;3(4):477-485.
42. Raimondo T, Puckett S, Webster TJ. Greater osteoblast and endothelial cell adhesion on nanostructured polyethylene and titanium. Int J Nanomedicine. 2010;7(5):647-652.

43. Lock J, Liu H. Nanomaterials enhance osteogenic differentiation of human mesenchymal stem cells similar to a short peptide of BMP-7. Int J Nanomedicine. 2011;6:2769-2777.

44. Allison KR, Brynildsen MP, Collins JJ. Metabolite-enabled eradication of bacterial persisters by aminoglycosides. Nature. 2011;73(7346): 216-220.

45. Kuehnert MJ, Kruszon-Moran D, Hill HA, et al. Prevalence of Staphylococcus aureus nasal colonization in the United States, 2001-2002. J Infect Dis. 2006;193(2):172-179.

46. Khang D, Kim SY, Liu-Snyder P, Palmore GT, Durbin SM, Webster TJ. Enhanced fibronectin adsorption on carbon nanotube/poly(carbonate) urethane: independent role of surface nano-roughness and associated surface energy. Biomaterials. 2007;28(32):4756-4768.

47. McHale G, Shirtcliffe NJ, Aqil S, Perry CC, Newton MI. Topography driven spreading. Phys Rev Lett. 2004;93(3):036102.

48. Lau KKS, Bico J, Teo KKB, et al. Superhydrophobic carbon nanotube forests. Nano Letters. 2003;3(12): 1701-1705.

49. Chow TS. Wetting of rough surfaces. J Phys Condens Matter. 1998;10(27):L445-L451.

50. Borgs C, De Coninck J, Kotecký R, Zinque M. Does the roughness of the substrate enhance wetting? Phys Rev Lett. 1995;74(12): 2292-2294.

51. Singh AJ, Vyas V, Patil R, et al. Quantitative characterization of the influence of the nanoscale morphology of nanostructured surfaces on bacterial adhesion and biofilm formation. PLos One. 2011; 6(9):e25029.
International Journal of Nanomedicine

\section{Publish your work in this journal}

The International Journal of Nanomedicine is an international, peerreviewed journal focusing on the application of nanotechnology in diagnostics, therapeutics, and drug delivery systems throughout the biomedical field. This journal is indexed on PubMed Central, MedLine, CAS, SciSearch ${ }^{\circledR}$, Current Contents $® /$ Clinical Medicine, Journal

\section{Dovepress}

Citation Reports/Science Edition, EMBase, Scopus and the Elsevier Bibliographic databases. The manuscript management system is completely online and includes a very quick and fair peer-review system, which is all easy to use. Visit http://www.dovepress.com/ testimonials.php to read real quotes from published authors. 